\title{
A PRELIMINARY STUDY OF THE EFFECTS OF GLUCOSAMINE SULPHATE AND CHONDROITIN SULPHATE ON SURGICALLY TREATED AND UNTREATED FOCAL CARTILAGE DAMAGE
}

\author{
Tunku Kamarul ${ }^{1}$, Sharaniza Ab-Rahim²*, Masjudin Tumin ${ }^{3}$, Lakshmi Selvaratnam ${ }^{4}$ and Tunku Sara Ahmad ${ }^{1}$ \\ ${ }^{1}$ Department of Orthopaedic Surgery (NOCERAL), University of Malaya, Kuala Lumpur, Malaysia \\ ${ }^{2}$ Faculty of Medicine, University Technology MARA, Shah Alam, Malaysia \\ ${ }^{3}$ Department of Orthopaedic Surgery and Traumatology, Sultanah Aminah Hospital, Johor Bahru, Johor, Malaysia \\ ${ }^{4}$ School of Medicine and Health Sciences, Monash University Sunway Campus, Sunway, Selangor, Malaysia
}

\begin{abstract}
The effects of Glucosamine Sulphate (GS) and Chondroitin Sulphate (CS) on the healing of damaged and repaired articular cartilage were investigated. This study was conducted using 18 New Zealand white rabbits as experimental models. Focal cartilage defects, surgically created in the medial femoral condyle, were either treated by means of autologous chondrocyte implantation (ACI) or left untreated as controls. Rabbits were then divided into groups which received either $\mathrm{GS}+/-\mathrm{CS}$ or no pharmacotherapy. Three rabbits from each group were sacrificed at 12 and 24 weeks post-surgery. Knees dissected from rabbits were then evaluated using gross quantification of repair tissue, glycosaminoglycan (GAG) assays, immunoassays and histological assessments. It was observed that, in contrast to untreated sites, surfaces of the ACI-repaired sites appeared smooth and continuous with the surrounding native cartilage. Histological examination demonstrated a typical hyaline cartilage structure; with proteoglycans, type II collagen and GAGs being highly expressed in repair areas. The improved regeneration of these repair sites was also noted to be significant over time (6 months vs. 3 months) and in GS and GS+CS groups compared to the untreated (without pharmacotherapy) group. Combination of ACI and pharmacotherapy (with glucosamine sulphate alone/ or with chondroitin sulphate) may prove beneficial for healing of damaged cartilage, particularly in relation to focal cartilage defects.
\end{abstract}

Keywords: Animal models, cartilage repair, chondrocytes, collagens, proteoglycans

\footnotetext{
*Address for correspondence:

Sharaniza Ab-Rahim

Faculty of Medicine, University of Technology MARA

Level 20, Tower 2 S\&T Complex

Shah Alam Selangor 40450

Malaysia
}

E-mail: sharaniza_abrahim@yahoo.com

\section{Introduction}

Traumatic articular cartilage injuries of the knee, as a result of acute and repetitive impact loading or rotational force of the joint surface, contribute up to $50 \%$ (Piasecki et al., 2003; Shelbourne et al., 2003) of all cartilage related diseases. Although there have been reports of limited spontaneous repair in damaged cartilage, these defects generally do not undergo complete repair (Piasecki et al., 2003; Shelbourne et al., 2003; Davis and Jones, 2004). To improve the healing process, a number of orthopaedic surgical procedures, including sub-chondral drilling, abrading and microfracture have been previously introduced. All of these techniques claim to promote hyaline (or at least hyaline-like) cartilage repair (O’Driscoll, 1998; Bentley et al., 2003; Shelbourne et al., 2003). However, long-term studies have demonstrated that these techniques only produce modest clinical outcomes, with many of the repaired sites filled with fibrocartilaginous tissue (Erggelet et al., 2003; Horas et al., 2003; Steadman et al., 2003a; Steadman et al., 2003b). These fibrocartilage tissues delaminate hyaline articular cartilage during motion, causing irreversible damage to the opposing joint surface (Kim et al., 1991; O'Driscoll, 1998; Wang, 2002; Erggelet et al., 2003; Steadman et al., 2003a; Steadman et al., 2003b). Alternative means of cartilage repair by transplanting hyaline cartilage from unaffected sites have also met with limited success due to a variety of reasons. These include restricted amounts of cartilage available from donor sites, donor site morbidity, and incongruity of the repaired joint surfaces (O'Driscoll, 1998; Wang, 2002; Horas et al., 2003).

In response to these limitations, Brittberg and coresearchers (1994) introduced autologous chondrocyte transplantation (ACT) or autologous chondrocyte implantation (ACI), which employs tissue engineering concepts to promote biological repair in focal cartilage defects (Bentley et al., 2003; Erggelet et al., 2003; Wada et al., 2003; Yates, 2003). In addition to promoting restoration of larger defects, ACT has been shown to induce hyaline-like tissue regeneration (Brittberg et al., 1994; Brittberg, 1999; Brittberg et al., 2001). However, this method has inherent limitations, among which is the prolonged recovery period required before the repair sites are able to tolerate normal joint stresses. To overcome this problem, current studies focus on stepping up tissue healing by (1) introducing cell scaffolds that provide the biomechanical strength needed to withstand early 
exposure to joint stresses, or by (2) enhancing tissue differentiation through growth factor-induced cellular expression (Miura et al., 1994; Brittberg, 1999; Brittberg et al., 2001; Brittberg, 2008). Although the role of stimulating factors and hormones to increase phenotypic cell expression has been well established in various in vitro models, their clinical applications have not been as forthcoming (Miura et al., 1994; Mercy Tissue Engineering, 2002; Brittberg, 2008).

Glucosamine sulphate (GS) and chondroitin sulphate (CS) are two most frequently prescribed nutritional supplements for the treatment of osteoarthritis (Noack et al., 1994; Matheson and Perry, 2003; Richy et al., 2003), yet controversy surrounds their efficacy and definitive mechanism of action. In the extensive multicentre GAIT study (Sawitzke et al., 2009), GS combined with CS appeared to provide significant pain relief but only in the 'moderate-to-severe pain' subset of osteoarthritic patients. Indeed, these pharmacotherapies have not been indicated for focal cartilage lesions, nor have they been proven to benefit patients who have undergone cartilage repair procedures. In an attempt to establish the roles of these drugs for the aforementioned conditions, a study was conducted to determine the effects of glucosamine sulphate with/without chondroitin sulphate on (1) untreated focal damaged cartilage and, (2) cartilage which was repaired using ACI. The findings of this study would be helpful to ascertain the roles of these dietary supplements in the repair of traumatic focal cartilage defects or in accelerating the healing rate of ACI surgically repaired cartilage.

\section{Materials and Methods}

Eighteen $(\mathrm{N}=18)$ male New Zealand white rabbits aged between 14 to 16 weeks, weighing approximately $3.5 \pm 1$ $\mathrm{kg}$ were used in this study (involving a total of $36 \mathrm{knee}$ joints). The study conformed strictly to University regulations on animal experimentation, and was approved by the University of Malaya Animal Ethics Review Board (approval reference: OS/06/07/08/TKZ/A(R)).

Rabbits were randomly divided into 3 groups with 6 rabbits in each group ( $n=6$ ); Group 1 (without GS and CS/ control), Group 2 (GS) and Group 3 (GS + CS). A defect was created on both knee joints of each rabbit (36 knee joints). Implantation was carried out on the right knees of each rabbit after 3 weeks of defect creation. Three rabbits from each group were sacrificed at 3 months and another 3 rabbits from each group were sacrificed at 6 months postimplantation.

\section{Preoperative procedures and biopsy of articular cartilage}

Prior to surgery, the rabbits were anaesthetized with intravenous sodium pentobarbital (Rhone Merieux Ltd., Essex, UK). A preoperative dose of cefazolin $(33 \mathrm{mg} / \mathrm{kg})$ was given intravenously. Using a custom made chondrotome, a circular cartilage defect (measuring $5 \mathrm{~mm}$ width $\mathrm{x}$ approximately $2 \mathrm{~mm}$ depth) was created on the medial femoral condyle of each hind knee joint. The cartilage within the demarcated area was completely removed using a size 11 blade whilst maintaining the integrity of subchondral bone. Cartilage samples were sent immediately for cell (chondrocyte) culture in dedicated clean labs. The wound was surgically closed in layers using absorbable sutures (daxon 5/0).

\section{Chondrocyte culture}

Chondrocyte extraction was performed using a modified chondrocyte culture technique established previously (Kamarul et al., 2008). Finely minced cartilage tissues were digested overnight using Type II collagenase ( $0.6 \%)$. Cells released from the tissue were then centrifuged at $1200 \mathrm{rpm}$ prior to culture in DMEM/F-12 (1:1) media, supplemented with $10 \%$ foetal bovine serum (FBS) at a seeding density of $1 \times 10^{5}$ cells $/ \mathrm{ml}$ (and at 5\% $\mathrm{CO}_{2}$ ). After reaching confluence, dissociation with trypsin-EDTA was carried out prior to suspension of chondrocytes in $1.2 \%$ sodium alginate at a density of $10 \times 10^{6}$ cells $/ \mathrm{ml}$. Calcium alginate beads were formed by exposing drops of the cell suspension to $50 \mathrm{mM}$ calcium chloride for $10 \mathrm{~min}$. Newly formed beads were removed from the calcium chloride solution, rinsed with normal saline and placed onto cell culture plates and covered with culture medium.

\section{Implantation of chondrocyte-alginate constructs}

In the second stage of the procedure, repair of the rabbit right knee, was performed after 3 weeks to mimic conditions of an early repair. A periosteal flap of $7 \mathrm{~mm}$ diameter was harvested from the medial aspect of the proximal tibia of the same hind limb. The flap was then placed on top of the articular cartilage defect with the cambium layer facing the defect and anchored using 8-0 Vicryl absorbable sutures at intervals of 2-3 $\mathrm{mm}$ with the knots concealed beneath. A superior opening was left for placement of the chondrocytes. In vivo chondrocytealginate transplantation was performed as described by Mierisch et al. (2003). However, a slight modification was employed in this study. Two calcium alginate beads containing autologous chondrocytes (approximately $5 \mathrm{x}$ $10^{4}$ cells/bead) acquired from the same rabbits were placed into the defective sites underneath the periosteal covering. The superior opening of the periosteal flap was sutured followed by wound closure using absorbable sutures (daxon 5/0).

\section{Gavage}

Gavage was carried out via insertion of a nasogastric tube (size 14) into the rabbit oesophagus $(20 \mathrm{~cm}$ from the mouth orifice) to ensure the drugs were fully administered. Rabbits in Group 1 were gavaged with normal saline (Control Group), Group 2 was gavaged with $120 \mathrm{mg}$ /day glucosamine sulphate (GS Group), and Group 3 was gavaged with $120 \mathrm{mg}$ /day glucosamine sulphate and 100 $\mathrm{mg}$ /day chondroitin sulphate (GS + CS Group). These drugs were administered daily until the time of sacrifice.

The doses in rabbits were calculated on the basis of the usual recommended doses in humans as previously described (Tiraloche et al., 2005; Herrero-Beaumont et al., 2008). Normal human consumption is $1500 \mathrm{mg} /$ day 

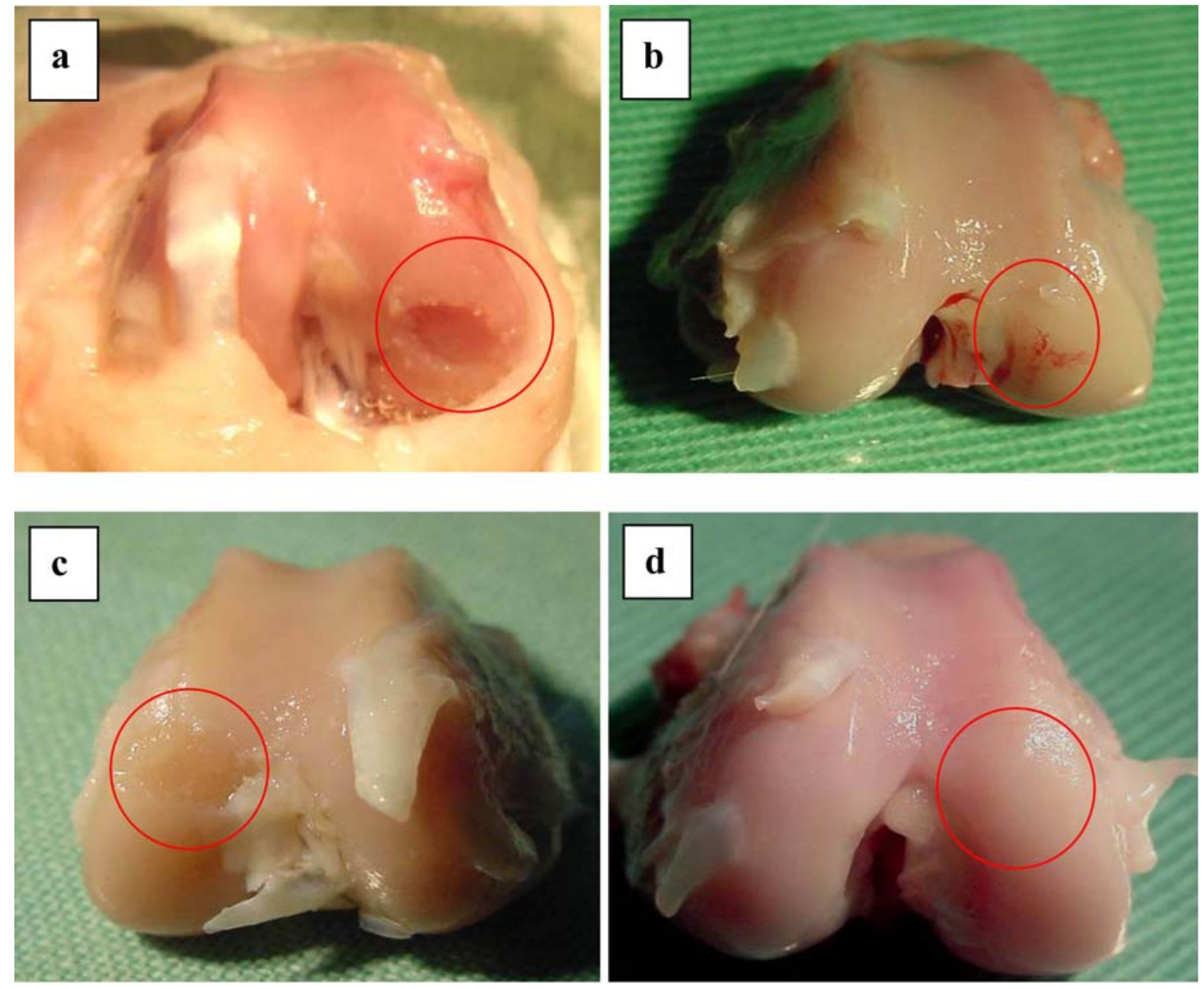

Figure 1: Examples of gross appearances of the knee articular cartilage on the femoral side of an adult New Zealand White rabbit (Group 3). Plate (a) demonstrating the defect created on the right knee before implantation (red circle); (b) right knee (repaired) at 3 months post-implantation showing completely filled defect covered with regenerated cartilage surface (red circle); (c) left (unrepaired) knee of the same rabbit showing defect filled with non-shiny/denuded irregular cartilage surface (red circle). In comparison to rabbits at 6 months, (d) the damage in the right knee (repaired) demonstrated almost complete healing with minimal cartilage defect visible.

of GS and $1200 \mathrm{mg} /$ day for CS therefore, approximately about $21.5 \mathrm{mg} / \mathrm{kg} / \mathrm{day}$ of GS and $17 \mathrm{mg} / \mathrm{kg} /$ day were given daily for $5 \mathrm{~kg}$ rabbit.

\section{Sacrifice}

Three $(n=3)$ rabbits from each treatment group were sacrificed at 12 and 24 weeks after chondrocyte transplantation respectively. Rabbits were sacrificed by intravenous sodium pentobarbitone overdose. Both femurs were dissected proximally by disarticulating the hip joint, after which the medial femoral condyle was then separated by transecting the femur at the supracondylar region. Macroscopic evaluation (using the Brittberg/ICRS visual histological assessment) (Mainil-Varlet et al., 2003) followed by histological analysis (using modified O'Driscoll/ICRS histological grading) (O'Driscoll et al., 1988; Mainil-Varlet et al., 2003) and sulphated glycosaminoglycan (S-GAG) assay were performed.

\section{Biochemical assay for glycosaminoglycans}

Each specimen (area of created defect) was cut into two. One half of the specimen was dissected into small pieces using a scalpel prior to digestion. Enzymatic digestion was achieved by using Radio-immunoprecipitation Assay (RIPA) buffer ( $1 \mathrm{ml}$ ) supplemented with protease inhibitor for $1 \mathrm{~h}$. The buffer was used to extract total protein from the cells to determine total protein content of the specimen enabling correction or normalisation of the GAG level in each sample. The cell lysate was divided into two, $900 \mu 1$ used for Glycosaminoglycan (GAG) and $100 \mu \mathrm{l}$ for protein content determination using a Blyscan ${ }^{\mathrm{TM}}$ Assay Kit (Bicolor, Belfast, Northern Ireland) (Farndale et al., 1986) and Bio-Rad (Hercules, CA, USA) DC® Protein Assay (Kamarul et al., 2008), respectively. Absorbance was read at $656 \mathrm{~nm}$ (for $\mathrm{GAG}$ ) and at $750 \mathrm{~nm}$ (for protein) wavelength using spectrophotometry and compared to a standard plot derived from shark chondroitin sulphate to determine the GAG content. The level of GAG $(\mu \mathrm{g})$ in each $\mathrm{mg}$ protein was then measured following the manufacturer's recommendation.

\section{Histological examination}

The second half of the specimen was used for histological assessment. Similar joint specimens were fixed in $10 \%$ phosphate-buffered formalin (4\% formaldehyde) for at least $24 \mathrm{~h}$, followed by decalcification and embedding in 
Table 1: Mean values of the Brittberg, Modified O'Driscoll score and GAG quantification of the repaired cartilage comparing the different groups at different times of analysis. Values are mean \pm standard deviation (SD) and 95\% confidence intervals in parentheses.

\begin{tabular}{|c|c|c|c|c|}
\hline \multirow{3}{*}{ Groups } & \multicolumn{4}{|c|}{ Brittberg Scores } \\
\hline & \multicolumn{2}{|c|}{ Right Knee } & \multicolumn{2}{|c|}{ Left Knee } \\
\hline & 12 weeks $(n=3)$ & 24 weeks $(n=3)$ & 12 weeks $(n=3)$ & 24 weeks $(n=3)$ \\
\hline $\begin{array}{l}\text { Group1; No } \\
\text { Pharmacotherapy }\end{array}$ & $\begin{array}{l}4.67 \pm 0.58 \\
(3.2-6.1)\end{array}$ & $\begin{array}{c}5.00 \pm 0.00 \\
\quad(\text { n.a })\end{array}$ & $\begin{array}{c}0.00 \pm 0.00 \\
\text { (n.a) }\end{array}$ & $\begin{array}{c}1.67 \pm 0.58 \\
(0.2-3.1)\end{array}$ \\
\hline Group 2; GS & $\begin{array}{c}6.33 * \pm 0.58 \\
(4.9-7.8)\end{array}$ & $\begin{array}{c}8.33 * \pm 0.58 \\
(6.9-9.8)\end{array}$ & $\begin{array}{c}2.33 \pm 0.58 \\
(0.9-3.8)\end{array}$ & $\begin{array}{c}3.00 \pm 0.00 \\
\quad \text { (n.a) }\end{array}$ \\
\hline Group 3; GS + CS & $\begin{array}{c}7.00 * \pm 1.00 \\
(4.5-9.5)\end{array}$ & $\begin{array}{c}8.33 * \pm 1.53 \\
(4.5-12.1)\end{array}$ & $\begin{array}{c}3.33 \pm 0.58 \\
(1.9-4.8)\end{array}$ & $\begin{array}{c}3.33 \pm 0.58 \\
(1.9-4.8)\end{array}$ \\
\hline \multirow{3}{*}{ Groups } & \multicolumn{4}{|c|}{ GAG values in $\mu \mathrm{g} / \mathrm{mg}$ protein } \\
\hline & \multicolumn{2}{|c|}{ Right Knee } & \multicolumn{2}{|c|}{ Left Knee } \\
\hline & 12 weeks $(n=3)$ & 24 weeks $(n=3)$ & 12 weeks $(n=3)$ & 24 weeks $(n=3)$ \\
\hline $\begin{array}{l}\text { Group1; No } \\
\text { Pharmacotherapy }\end{array}$ & $\begin{array}{c}0.84 \pm 0.17 \\
(0.4-1.3)\end{array}$ & $\begin{array}{c}1.37 \pm 0.53 \\
(0.1-2.7)\end{array}$ & $\begin{array}{c}0.78 \pm 0.19 \\
(0.3-1.2)\end{array}$ & $\begin{array}{c}0.84 \pm 0.34 \\
(0.0-1.7)\end{array}$ \\
\hline Group 2; GS & $\begin{array}{l}1.02 \pm 0.12 \\
(0.7-1.3)\end{array}$ & $\begin{array}{c}2.72 * \pm 0.78 \\
(0.8-4.6)\end{array}$ & $\begin{array}{c}0.76 \pm 0.11 \\
(0.5-1.0)\end{array}$ & $\begin{array}{c}1.50 \pm 0.45 \\
(0.4-2.6)\end{array}$ \\
\hline Group 3; GS + CS & $\begin{array}{l}1.49 \pm 0.74 \\
(0.3-3.3)\end{array}$ & $\begin{array}{c}3.25^{*} \pm 0.29 \\
(2.5-4.0)\end{array}$ & $\begin{array}{c}0.88 \pm 0.24 \\
(0.3-1.5)\end{array}$ & $\begin{array}{c}1.89 \pm 0.43 \\
(0.8-2.9)\end{array}$ \\
\hline \multirow{3}{*}{ Groups } & \multicolumn{4}{|c|}{ Modified O'Driscoll scores } \\
\hline & \multicolumn{2}{|c|}{ Right Knee } & \multicolumn{2}{|c|}{ Left Knee } \\
\hline & 12 weeks $(n=3)$ & 24 weeks $(n=3)$ & 12 weeks $(n=3)$ & 24 weeks $(n=3)$ \\
\hline $\begin{array}{l}\text { Group1; No } \\
\text { Pharmacotherapy }\end{array}$ & $\begin{array}{l}8.67 \pm 3.79 \\
(0.7-18.1)\end{array}$ & $\begin{array}{c}10.00 \pm 3.00 \\
(2.5-17.4)\end{array}$ & $\begin{array}{c}5.67 \pm 1.53 \\
(1.9-9.5)\end{array}$ & $\begin{array}{c}3.67 \pm 1.16 \\
(0.8-6.5)\end{array}$ \\
\hline Group 2; GS & $\begin{array}{c}14.33 * \pm 6.11 \\
(0.8-29.5)\end{array}$ & $\begin{array}{c}14.67 * \pm 2.52 \\
(8.4-20.9)\end{array}$ & $\begin{array}{l}8.00 \pm 5.29 \\
(5.1-21.1)\end{array}$ & $\begin{array}{l}7.67 \pm 4.73 \\
(4.1-19.4)\end{array}$ \\
\hline Group 3; GS + CS & $\begin{array}{c}14.67 * \pm 5.03 \\
(0.8-27.2)\end{array}$ & $\begin{array}{c}18.67 * \pm 1.53 \\
(14.9-22.5)\end{array}$ & $\begin{array}{c}8.00 \pm 6.56 \\
(8.3-24.3)\end{array}$ & $\begin{array}{l}7.33 \pm 5.51 \\
(6.3-21.0)\end{array}$ \\
\hline
\end{tabular}

n.a - not available.

* $P<0.05$ when compared with Group 1 at the respective time point.

paraffin such that $5 \mu \mathrm{m}$ thick sections could be cut. Using standard histochemical techniques, histological sections were stained with Haematoxylin \& Eosin (H\&E) and Safranin-O. Immunostaining for type II collagen was performed on histological sections following the manufacturer's instructions (DAKO ${ }^{\circledR}$ TBS) and using a mouse monoclonal primary antibody against type II collagen (Calbiochem, Germany) with specificity to human, rabbit, rat and bovine tendon/cartilage (Kivirikko, 1993).

\section{Statistical analysis}

The mean Brittberg score (i.e., a modification from the ICRS Cartilage Injury Evaluation Package [www.cartilage.org]) (Peterson et al., 2000; Mainil-Varlet et al., 2003), modified O'Driscoll scores (O'Driscoll et al., 1988), histological scores and GAG (Farndale et al., 1986) levels were calculated from samples of both knees $(n=36)$. Inter- and intra-group differences were analysed using non-parametric tests, including Kruskal-Wallis and Mann-Whitney U tests. The statistical package software
SPSS (version 13.0) was used for the analyses with statistical significance set at $5 \%(p \leq 0.05)$.

\section{Results}

Assessment was carried out to compare the effects of pharmacotherapy between groups; Group 1 (without GS and CS i.e. control), Group 2 (GS) and Group 3 (GS + $\mathrm{CS})$. Effects of surgical intervention, ACI repaired site (right knee) and unrepaired site (left knee) of each group to the pharmacotherapy treated rabbits were also assessed.

\section{Gross morphological analysis}

The defect sites in the untreated (left) knees of all 3 groups demonstrated minimal repair with uneven and irregular surfaces noted. These defects appeared to be filled with whitish regenerative tissue denoting ongoing repair. In ACI treated sites (right knees) of Groups 2 and 3, the regenerative tissue appeared thicker than in Group 1 and more closely resembled the adjacent articular cartilage (Fig. 

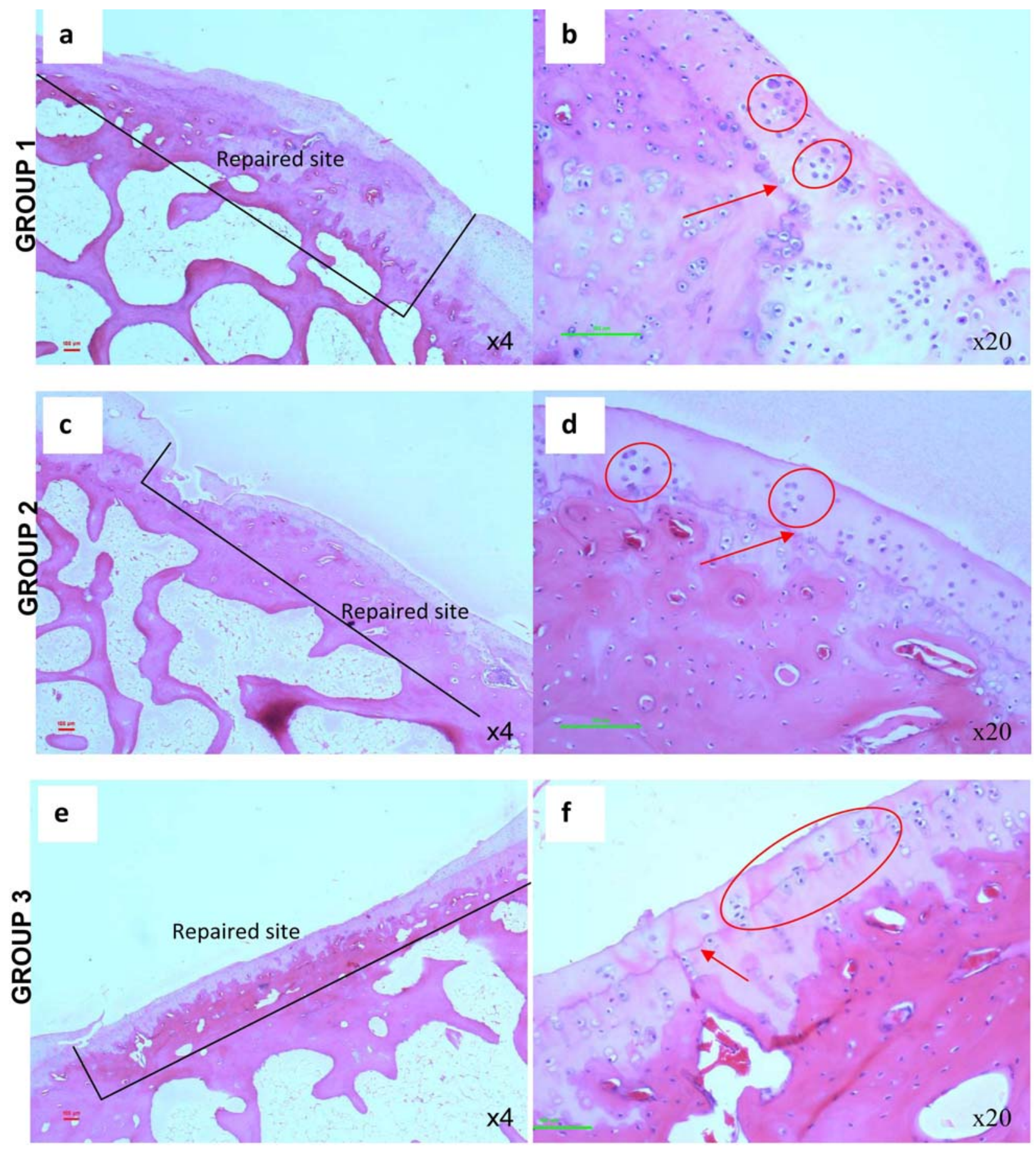

Figure 2: Haematoxylin and Eosin stained sections of the repaired sites in the different groups of adult New Zealand White rabbit knee joints at 3 months post-implantation. Plate (a), (c) and (e) are images of the repaired (right) knees according to the different groups (x4). Higher magnifications (x20) of these areas are illustrated in plates (b), (d) and (f). Cell clustering with columnar cells arrangements can clearly be observed (as indicated by the red circles) in plates (b), (d) and (f). The tide marks in cartilage tissue are indicated by the red arrows. Scale bars: $100 \mu \mathrm{m}$.

1). Although some areas showed mild central depressions in these repair sites, this tissue appeared to be mostly smooth and integrated with the surrounding cartilage with no apparent demarcating borders. No periosteal thickening was seen in any of the ACI treated sites.

Significant differences in the mean Brittberg scores between the different pharmacological groups (Group 2 and 3) were noted when knees of the respective sides were compared. Differences in the mean Brittberg scores in the right knee were found to be significant when comparison were made between the control group (Group 1) and those receiving oral pharmacotherapy at 12 weeks i.e. Groups 1 vs. 2 and Groups 1 vs. 3 (Mann Whitney-U test: $p=0.04$ and $p=0.03$ respectively). Similar $p$ values at were also observed when comparison were made between groups 1 (control group) and $2(p=0.04)$; and between groups 1 and $3(p=0.03)$ at 24 weeks. In Group 1, the mean Brittberg grading scores (Table 1) were 5-fold (at 3 months) and 3- 

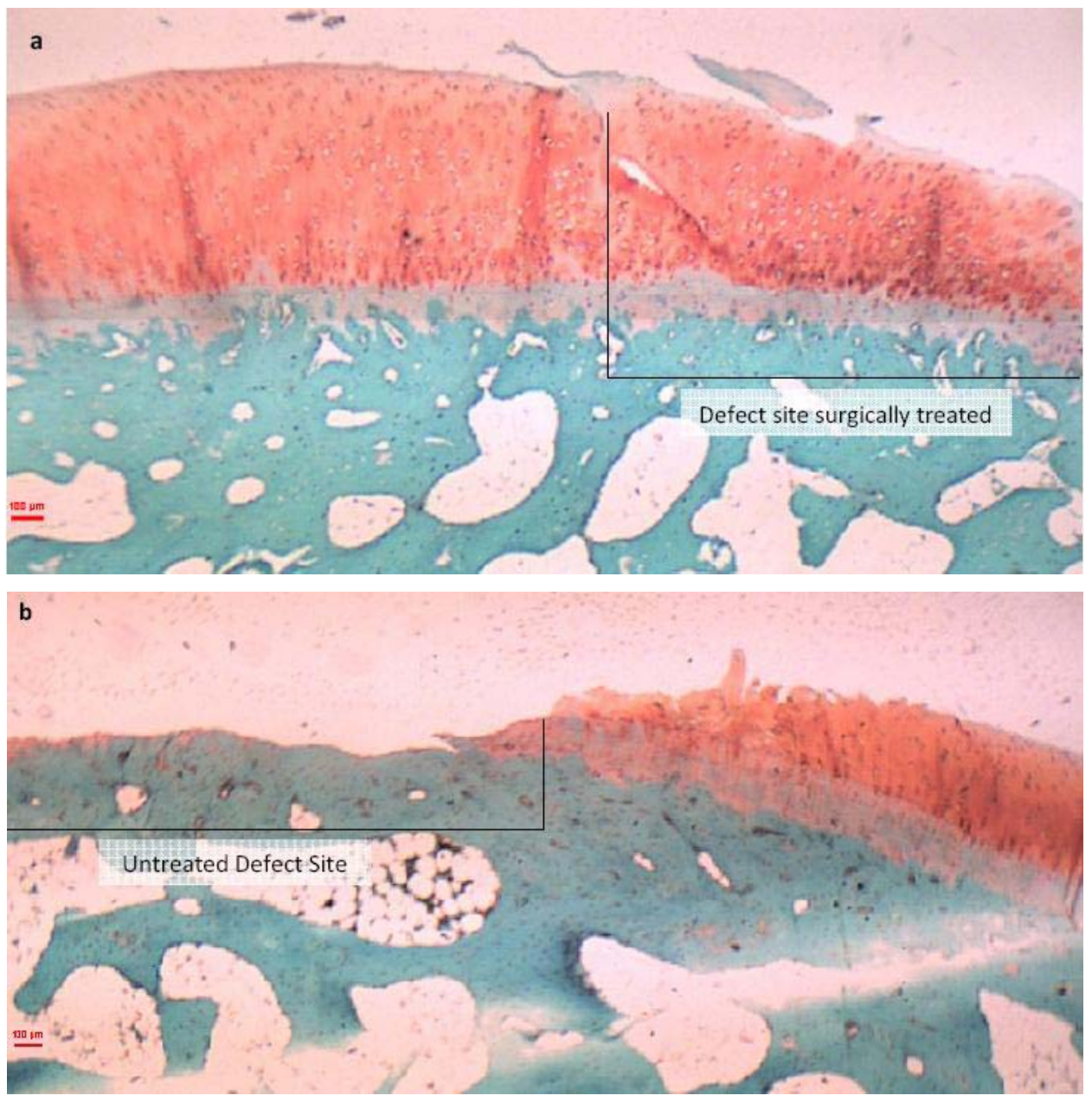

Figure 3: Photomicrograph of typical sections of Safranin-O stained knee joints of Group 1 adult New Zealand White rabbit at 6 months post-implantation (a) Right knee (implanted) showing cartilage fill with proteoglycan secreted extensively at the defect site; (b) Left knee (control) showing absence of repair at the defect site. Scale bars: $100 \mu \mathrm{m}$.

fold (at 6 months) higher in the implanted knees (right side) than that of the non implanted left knees.

\section{Histological analysis and cartilage repair score}

In the ACI treated sites, hyaline cartilage repair was evident in both H\&E and Safranin-O stained sections at 3 and 6 months (Fig. 2, Fig. 3). At 12 weeks, chondrocytes appeared in cluster formation with some columnar arrangements seen in only group 3 . The typical appearance of native cartilage was lacking in all other groups. At 24 weeks however, chondrocyte columns with substantial pericellular matrix formation could be seen. There was intense staining of Safranin-O noted on histological sections of the right knee, indicating strong proteoglycan expression within the matrix (Fig. 3). There was marked expression of type II collagen in the implanted side, which appeared to be largely homogenous with the surrounding native cartilage (Fig. $4)$. The untreated left knees showed contrasting observations (Fig. 4).

Using the modified O'Driscoll scores (Table 2), significant differences were observed between the ACI treated (right) knees in the different groups (Kruskall-Wallis test; $p=0.026)$. However, no significant differences were noted between the various groups in the untreated left knees (Kruskall-Wallis test; $p=0.53$ ). The mean score values for each group is summarized in Table 1. In the control knees, there was little or no obvious repair tissue or cell in-growth observed in the defective sites. Histological examination demonstrated intense staining with Safranin-O in ACI-treated sites in Group 3, indicating that proteoglycans within the ECM were highly expressed. Immunolocalisation of type II collagen showed homogenous distribution of collagen in the implanted knees, which was similar to the distribution pattern in surrounding native articular cartilage. In Groups 2 and 3, O’Driscoll scores (Table 1) demonstrated a 2-fold (at both 3 and 6 months) increase in chondrocyte-implanted knees (right side) but were minimal (less than 1 fold increase) in the untreated knees.

\section{Biochemical analysis}

Joint defects which underwent ACI (right knees) healed significantly better than non-treated sites (left knees) in all groups. Quantification of GAG deposition correlated with histological assessment and also with increased type II collagen expression seen on immunohistochemical 

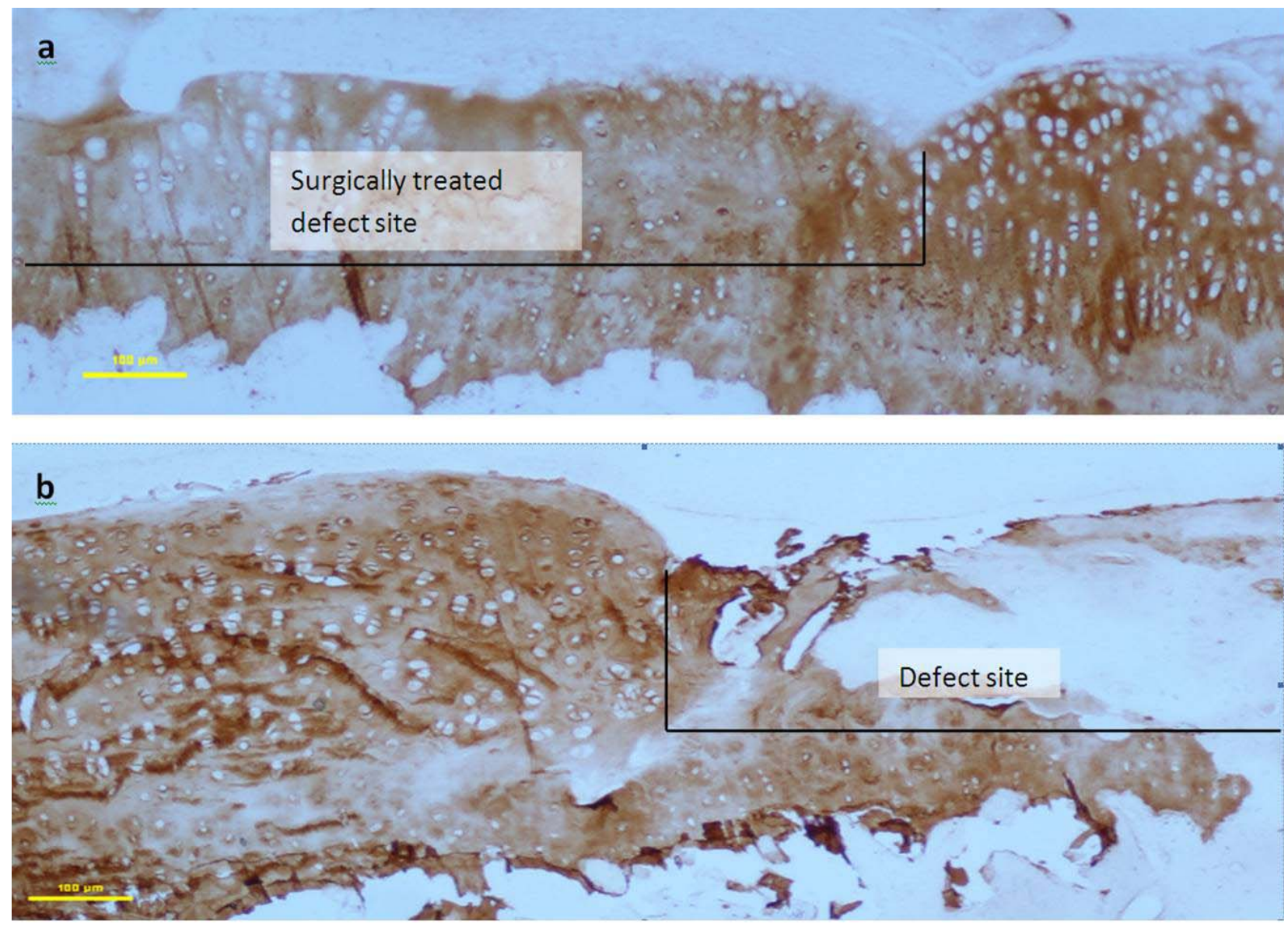

Figure 4: Photomicrographs of immunostained histological sections against type II collagen in the repaired (a) and unrepaired (b) defect sites of Group 1 adult New Zealand White rabbit at 3 months post-implantation. Plate (a) demonstrate an abundance in type-II collagen expression at the repaired site (right knee) while in Plate (b), there is reduced type-II collagen expression within the defect site. Scale bars: $100 \mu \mathrm{m}$.

staining. Such structural and biochemical evidence of cartilage differentiation was progressively observed in these repair sites and found to be significant over time i.e. 3 months vs. 6 months.

Between the pharmacological groups, significant improvements were noted in the right knee between Group 1 to Groups 2 and 3 respectively (Mann Whitney U test: $p=0.047$ in both groups) at 24 weeks post-implantation. However, there were no significant differences between groups 2 and 3 for GAG levels. Although some improvement could be seen at 12 weeks when compared to Group 1, these differences were not statistically significant (Right knee: Group $2 p=0.18$; Group 3, $p=0.13$. Left knee: Group 2, $p=1.0$; Group 3, $p=0.83$ ). There were also no differences between GAG depositions in the left knees at 12 and 24 weeks (Please refer to Table 1).

\section{Discussion}

The use of autologous chondrocyte implantation (ACI) in our study produced significant cartilage healing in surgically created focal cartilage defects, as compared to non-treated cartilage controls. The quality of cartilage repair was further improved with administration of oral glucosamine sulphate (GS) with/without chondroitin sulphate (CS). Although the results of this study suggest that GS/GS+CS pharmacotherapies may promote the healing process in damaged and repaired articular cartilage, it is worth noting that surgical repair through ACI is required to elicit the significant healing when using these drugs. The role of oral pharmacotherapy alone for the treatment of non-repaired focal cartilage defects in this study was not convincing.

At present, there are two available forms of pharmacological preparations for the treatment of damaged cartilage: (1) injectables, which act locally into the joints, and (2) oral preparations, which act systemically. Intraarticular injection, such as corticosteroids and hyaluronic acid, have been suggested as treatments for articular cartilage damage; however, the positive results seen in the early stages of the therapy are usually short-lived. Oral therapy, namely GS and CS (Lippiello, 2003), have been claimed to be effective in stimulating articular cartilage healing in patients with osteoarthritis. However, this treatment has not been previously described for focal cartilage damage. In the present study, the use of these drugs appears to have a positive influence in the repair process although the pathophysiological mechanisms leading to repair remain unclear (Lippiello, 2003). In the 
Table 2: O'Driscoll histological and histochemical grading scale.

\begin{tabular}{|c|c|}
\hline & Score \\
\hline \multicolumn{2}{|l|}{ Nature of the predominant tissue } \\
\hline \multicolumn{2}{|l|}{ Cellular morphology } \\
\hline Hyaline articular cartilage & 4 \\
\hline Incompletely differentiated mesenchyme & 2 \\
\hline Fibrous tissue or bone & 0 \\
\hline \multicolumn{2}{|l|}{ Safranin-O staining of the matrix } \\
\hline Normal or nearly normal & 3 \\
\hline Moderate & 2 \\
\hline Slight & 1 \\
\hline None & 0 \\
\hline \multicolumn{2}{|l|}{ Structural characteristics } \\
\hline \multicolumn{2}{|l|}{ Surface regularity } \\
\hline Smooth and intact & 3 \\
\hline Superficial horizontal lamination & 2 \\
\hline Fissures $-25-100 \%$ of the thickness & 1 \\
\hline Severe disruption, including fibrillation & 0 \\
\hline \multicolumn{2}{|l|}{ Structural integrity } \\
\hline Normal & 2 \\
\hline Slight disruption, including cysts & 1 \\
\hline Severe disintegration & 0 \\
\hline \multicolumn{2}{|l|}{ Thickness } \\
\hline $100 \%$ of normal adjacent cartilage & 2 \\
\hline $50-100 \%$ of normal cartilage & 1 \\
\hline $0-50 \%$ of normal cartilage & 0 \\
\hline \multicolumn{2}{|l|}{ Bonding to the adjacent cartilage } \\
\hline Bonded at both ends of graft & 2 \\
\hline Bonded at one end, or partially at both ends & 1 \\
\hline Not bonded & 0 \\
\hline \multicolumn{2}{|l|}{$\begin{array}{l}\text { Freedom from cellular changes of degeneration } \\
\text { Hypocellularity }\end{array}$} \\
\hline Normal cellularity & 3 \\
\hline Slight hypocellularity & 2 \\
\hline Moderate hypocellularity & 1 \\
\hline Severe hypocellularity & 0 \\
\hline \multicolumn{2}{|l|}{ Chondrocyte clustering } \\
\hline No clusters & 2 \\
\hline$<25 \%$ of the cells & 1 \\
\hline $25-100 \%$ of the cells & 0 \\
\hline \multicolumn{2}{|l|}{ Freedom from degenerative changes in adjacent cartilage } \\
\hline Normal cellularity, no clusters, normal staining & 3 \\
\hline Normal cellularity, mild clusters, moderate staining & 2 \\
\hline Mild or moderate hypocellularity, slight staining & 1 \\
\hline Severe hypocellularity, poor or no staining & 0 \\
\hline
\end{tabular}

*Adapted from O’Driscoll et al., 1988.

past, the roles of these supplements have been queried, particularly in relation to whether direct metabolism can, in effect, aid the increase in production of cartilage proteoglycan sub-units (Laverty et al., 2005). Furthermore, it is also unclear how oral GS and CS reach the defective or repaired sites considering that cartilage itself is avascular (O’Driscoll, 1998; Bentley et al., 2003; Piasecki et al., 2003; Shelbourne et al., 2003). Although both drugs claim to possess chondroprotective properties, only GS has been widely described and studied in great detail (Noack et al., 1994; Matheson and Perry, 2003; Richy et al., 2003; Laverty et al., 2005). GS is an amino monosaccharide precursor that is incorporated, either directly or after conversion to galactosamine, into the disaccharide unit of glycosaminoglycans (GAGs) located in proteoglycans (PGs) of cartilage matrix (Mroz and Silbert, 2004). Clinical trials using GS for treating osteoarthritis have demonstrated that this supplement provides symptomatic relief, although slow acting (Noack et al., 1994; Matheson and Perry, 2003; Richy et al., 2003). Conversely, other studies have shown that GS produces no beneficial effect, possibly related to the variable source of GS used (Reginster et al., 2001).

Based on lab experiments, synovial fluid concentrations of GS are known to correlate with 
peripheral blood concentrations when GS is introduced intravenously or orally (Kim and Conrad, 1974; Setnikar and Rovati, 2001). Furthermore, orally administered radiolabelled glucosamine have been demonstrated to reach the joints successfully and metabolised by chondrocytes (Setnikar et al., 1984; Meulyzer et al., 2008). On the other hand, GS/CS present in synovial fluids may also be due to plasma ultrafiltration and cells at the fenestrated capillaries or the synovial lining may be the ones metabolising these drugs rather than chondrocytes (Meulyzer et al., 2008). This may explain previous observations by Laverty et al. that show only $\sim 10 \%$ increase of glucosamine concentration in synovial joint fluid was found following intravenous (IV) or nasogastric (NG) dosing as compared to serum concentrations (Meulyzer et al., 2008). This bioavailability was deemed to be insufficient to cause any improvement in cellular expressions or metabolic activity as demonstrated by others (Laverty et al., 2005; Meulyzer et al., 2008). For in vivo effects of glucosamine on chondrocytes to be significant, it has been demonstrated that the monosaccharide component of GS would have to "accumulate" in cartilage to levels at least 500 times higher than those present in the synovial fluid of patients receiving therapeutic dosages (Laverty et al., 2005; Meulyzer et al., 2008). This condition is therefore unlikely to occur even in patients exposed to prolonged use of GS (Reginster et al., 2001).

It has been postulated that GS may be preferentially "targeting" cartilage tissue, which results in the positive effect seen on cartilage homeostasis (Setnikar and Rovati, 2001; Meulyzer et al., 2008). Another possible reason may be due to the fact that GS provides improved metabolism in tissues other than articular joints (such as intestine, liver and potentially kidney) and thus, indirectly improves the function of chondrocytes (Setnikar and Rovati, 2001). This finding has been substantiated by a number of experiments in many independent laboratories, which have not uncovered any high-affinity binding partners for glucosamine in cartilage. It has been suggested instead that glucosamine behaves much like other freely diffusible nutrients (Kim and Conrad, 1974; Morales and Hascall, 1989; Noyszewski, 2001). Having noted the high serum levels of GS, this theory seems plausible as many glucosamine-mediated effects on cells (Dodge and Jimenez, 2003) are thought to be related to its known stimulation (as glucosamine-6-phosphate [GlcN6P]) of the intracellular hexosamine biosynthetic pathway (HBP) (Rumberger et al., 2003).

In comparison, $\mathrm{CS}$ is said to produce superior therapeutic effects than GS, although there have not been any large clinical studies that directly compares the effects of these two drugs (Das and Hamam, 2000; Dechant et al., 2005). More interestingly, there are also very few studies that describe the efficacy of a drug combination (i.e., GS-CS) in improving cartilage repair processes (Chan et al., 2005). The findings of our study appear to complement previous clinical studies in animals and in vitro conditions, demonstrating that: (1) combined therapy has been shown to have protective and beneficial effects in vitro by acting synergistically in stimulating the production of PGs in articular cartilage, while inhibiting the activity of the degradative enzymes (Dechant et al., 2005), and (2) in studies involving animal models, this combination is shown to exert a protective effect on cartilage degradation (Bassleer et al., 1998; Chan et al., 2005). However, these findings are not consistently supported by others, with many reports showing mixed results (Lipeela et al., 2000; Orth et al., 2002; Dodge and Jimenez, 2003; Ilic et al., 2003; Lippiello, 2003; Persiani et al., 2004). In one study involving 12 human subjects, it was even reported that the administration of a combination of these drugs lead to the reduction of GS bioavailability in plasma (Lipeela et al., 2000). It is interesting to note that others have shown combining GS with CS yields a synergistic rather than additive effect (Hungerford, 1998; Sandy et al., 1998) (which is clearly demonstrated in our own study).

Using young rabbits for the implantation work however, has its own limitations. The possibility of an agerelated wound healing process in articular cartilage may have influenced the results in this study. However, although rabbits that were not fully matured (14 to 16 weeks) were utilised for this work, their age was close to that of maturity (20 weeks). In addition, post-implantation healing was analysed at 3 and 6 months, by which time these rabbits had clearly reached maturity ( $>20$ weeks).

Based on the results of our study and that reported by others (Homandberg et al., 2006), it is valid to say that there may be a functional role for glucosamine (GS) and chondroitin sulphate (CS) in the repair process of damaged cartilage. It is also evident that by supplementing rabbits with GS and CS, there were significant improvements to cartilage regeneration, although adding CS to subjects already receiving GS did not appear to provide significant improvements. In the clinical setting, we therefore advocate glucosamine sulphate be considered as a possible adjunct treatment to patients undergoing autologous chondrocyte implantation (ACI), as the effect of these supplements in enhancing joint repair processes appears to be promising (this is a novel finding). For future protocols involving rehabilitation of patients undergoing ACI, incorporation of GS (and even CS) either peri-operatively and/or postoperatively may need to be seriously considered in order to optimise cartilage repair, and thus reduce the recovery time for these patients. However, further study involving a larger sample population may be needed to confirm definitively the role of these nutrition supplements on cartilage repair.

\section{Conclusions}

In summary, based on the gross (Brittberg score), histological (O'Driscoll score) and biochemical (GAG content) analyses of autologous chondrocyte implantation treated sites, both glucosamine sulphate alone or with chondroitin sulphate produced statistically significant improvements in cartilage regeneration. However, surgical intervention through ACI, appears to be still necessary for damaged cartilage to undertake significant tissue repair. 
The use of oral pharmacotherapy especially glucosamine, may assist in improving the cartilage repair process, although the addition of CS to GS supplementation may not provide further advantage. Although further study is warranted, combination of ACI and pharmacotherapy may prove beneficial for healing of damaged cartilage, particularly in relation to focal cartilage defects.

\section{Acknowledgements}

The Tissue Engineering Group at University Malaya Medical Centre would like to acknowledge the assistance provided by Ms. Azeera Abu Bakar, Sukanya Subramaniam, Mr. Rasanayagam and Mdm. Lim Saw Kim to this study. This project was funded by University Malaya - Vote F research grant/ IRPA Research grant under the $8^{\text {th }}$ Malaysian Plan - F0136/2005B and 36-02-03-6037/Oracle 8301037. Our thanks also extend to Antah Pharma Sdn Bhd. for donating the oral glucosamine used in this project and Institute of Medical Molecular Biotechnology (IMMB) UiTM for the facilities provided.

\section{References}

Bassleer C, Rovati L, Franchimond P (1998) Stimulation of proteoglycan production by glucosamine sulfate in chondrocyte isolate from human osteoarthritis articular cartilage in vitro. Osteoarthritis Cartilage 6: 427 434.

Bentley G, Biant LC, Carrington RW, Akmal M, Goldberg A, Williams AM, Skinner JA, Pringle J (2003) A prospective, randomized comparison of autologous chondrocyte implantation versus mosaicplasty for osteochondral defects in the knee. J Bone Joint Surg Br 85-B: 223-230.

Brittberg M (1999) Autologous chondrocyte transplantation. Clin Orthop Relat Res 367(Suppl): S147155.

Brittberg M (2008) Autologous chondrocyte implantation - Technique and long term follow up. Injury. Int. J Care Injured 39: S40-49.

Brittberg M, Lindah A, Nilsson A, Ohlsson C, Isaksson O, Peterson L (1994) Treatment of deep cartilage defects in the knee with autologous chondrocyte transplantation. N Eng J Med 331: 889-895.

Brittberg M, Tallheden T, Sjogren-Jansson E, Lindahl A, Peterson L, Autologous chondrocytes used for articular cartilage repair: An update (2001) Clin Orthop Relat Res 391(Suppl): S337-348.

Chan PS, Caron JP, Orth MW (2005) Effect of glucosamine and chondrotin sulfate on regulation of gene expression of proteolytic enzymes and their inhibitors in IL-1 challenged bovine articular cartilage explant. Am J Vet Res 66: 1870-1877.

Das AJ, Hamam TA (2000) Efficacy of combination of FCHG49 ${ }^{\mathrm{TM}}$ glucosamine hydrochloride, TRH122 ${ }^{\mathrm{TM}}$ low molecular weight sodium chondroitin sulfate maganesse ascorbate in the management of knee osteoarthritis. Osteoarthritis Cartilage 8: 343-350.
Davis JT, Jones DG (2004) Treatment of knee articular cartilage injuries. Curr Opin Orthopaed 15: 92-99.

Dechant JE, Baxter GM, Frisbie DD, Trotter GW, McIlwraith CW (2005) Effect of glucosamine hydrochloride and chondroitin sulphate, alone and in combination on normal and IL-1 conditioned equine articluar cartilage explant metabolism. Equine Vet J 37: 227-231.

Dodge GR, Jimenez SA (2003) Glucosamine Sulfate modulates the levels of aggrecan and MMPs-3 synthesized by cultured human osteoarthritic articular chondrocytes. Osteoarthritis Cartilage 11: 424-432.

Erggelet C, Sittinger M, Lahm A (2003) The arthroscopic implantation of autologous chondrocytes for the treatment of full-thickness cartilage defects of the knee joint. Arthroscopy 19: 108-110.

Farndale RW, Buttle DJ, Barrett AJ (1986) Improved quantification and discrimination of sulfated glycosaminoglycans by use of dimethylmethylene blue. Biochim Biophys Acta 883: 173-177.

Herrero-Beaumont G, Marcos ME, Sanchez-Pernaute O, Granados R, Ortega LL, Montell E, Verges J, Egido J, Largo R (2008) Effect of chondroitin sulphate in a rabbit model of atherosclerosis aggravated by chronic arthritis. Br J Pharmacol 154: 843-851.

Homandberg GA, Guo D, Ray M, Ding L (2006) Mixture of glucosamine and chondoitin sulfate reverse fibronectin fragment mediated damage to cartilage more effectively than either agent alone. Osteoarthritis Cartilage 14: 793-806.

Horas U, Pelinkovic D, Herr G, Aigner T, Schnettler R (2003) Autologous chondrocyte implantation and osteochondral cylinder transplantation in cartilage repair of the knee joint: a prospective, comparative trial. J Bone Joint Surg Am 85: 185-192.

Hungerford DS (1998) Treating osteoarthritis with chondroprotective agents. Orthopedic Special Edition 1: 39-42.

Ilic MZ, Martinac B, Hndley CJ (2003) Effects of longterm exposure to glucosamine and mannoramine on aggrecan degradation in articular cartilage. Osteoarthritis Cartilage 11: 613-622.

Kamarul T, Selvaratnam L, Masjuddin T, Ab-Rahim S, Ng C, Chan KY, Ahmad TST (2008) Autologous chondrocyte transplantation in the repair of full-thickness focal cartilage damage in rabbits. J Orthop Surg 16: 8487.

Kim HK, Moran ME, Salter RB (1991) The potential for regeneration of articular cartilage in defects created by chondral shaving and subchondral abration. An experimental investigation in rabbit. J Bone Joint Surgery Am 73: 1301-1315.

Kim JJ, Conrad HE (1974) Effect of D-glucosamine concentration on the kinetics of mucopolysaccharide biosynthesis in cultured chick embryo vertebral cartilage. J Biol Chem 249: 3091-3097.

Kivirikko KI (1993) Collagens and their abnormalities in a wide spectrum of diseases. Ann Med 25: 113-126.

Laverty S, Sandy JD, Celeste C, Vachon P, Marier JF, Plass AH (2005) Synovial fluid levels and serum pharmacokinetics in a large animal model follow treatment 
with oral glucosamine at clinically relevant doses. Arthritis Rheum 52: 181-191.

Lipeela L, Woodward J, Karpman R, Hammad TA (2000) In vivo chondroprotection and metabolic synergy of glucosamine and chondroitin sulfate. Clinical Orthopaedics 381: 229-240.

Lippiello L (2003) Glucosamine and chondroitin sulfate: Biological response modifiers of chondrocyte under simulate condition of joint stress. Osteoarthritis Cartilage 11: 335-342.

Mainil-Varlet P, Aigner T, Brittberg M, Bullough P, Hollander A, Hunziker A (2003) Histological assessment of cartilage repair. J Bone Joint Surg Am 85-A: 45-57.

Matheson AJ, Perry CM (2003) Glucosamine: A review of its use in the management of osteoarthritis. Drugs Aging 20: 1041-1060.

Mercy Tissue Engineering (2002) ACI: Autologous Chondrocyte Implantation. Review of Current Literature. International Meeting Presentations and Clinical Results.

Meulyzer M, Vachon P, Beaudry F, Vinardell T, Richard H, Beauchamp G, Laverty S (2008) Comparison of pharmacokinetics of glucosamine and synovial fluid levels following administration of glucosamine sulfate or glucosamine hydrochloride. Osteoarthritis Cartilage 16: 973-979.

Mierisch CM, Wilson HA, Turner MA, Milbrandt TA, Berthoux L, Hammarskjöld M-L (2003) Chondrocyte transplantation into articular cartilage defects with use of calcium alginate: The fate of the cells. J. Bone Joint Surg Am 85: 1757-1767.

Miura Y, Fitzsimmons JS, Comisso CN, Gallay SH, O'Driscoll SW (1994) Enhancement of periosteal chondrogenesis in vitro-dose response for TGF- $\beta 1$. Clin Orthop Relat Res 301: 271-280.

Morales TI, Hascall VC (1989) Factors involved in regulation of proteoglycan metabolism in articular cartilage. Arthritis Rheum 32: 1197-1201.

Mroz PJ, Silbert JE (2004) Use of ${ }^{3} \mathrm{H}-$ Glucosamine and ${ }^{55} \mathrm{~S}$-Sulfate with cultured human chondrocyte to determine the effects of glucosamine concentration on formation of chondroitin sulfate. Arthritis Rheum 50: 3574-3579.

Noack W, Fischer M, Forster KK, Rovati LC, Setnikar L (1994) Glucosamine sulfate in osteoarthritis of the knee. Osteoarthritis Cartilage 2: 51-59.

Noyszewski EA, Wrablewski K, Dodge GR, Kodchodker S, Beers J, Sarma AV, Reddy R (2001) Preferential incorporation of glucosamine moities of chondroitin sulfate in articular cartilage explants. Arthritis Rheum 44: 1089-1095.

O'Driscoll, SW (1998) Current concepts review: the healing and regeneration of articular cartilage. J Bone Joint Surg Am 80:1795-1812.

O'Driscoll SW, Keeley FW and Salter RB (1988) Durability of regenerated articular cartilage produced by free autogenous periosteal grafts in major full-thickness defects in joint surfaces under the influence of continuous passive motion. J Bone Joint Surg Am 70-A: 595-606.

Orth MW, Peters TL, Hawkins JN (2002) Inhibition of articular cartilage degradation by glucosaminehydrochloride and chondroitin sulphate. Equine Vet J Suppl 34: 224-229.
Persiani S, Rovati LC, Pastroini E, Locatelli M, Glacovelli G, Pagonini D, Roda A (2004) Pharmacokinetics of glucosamine in man after oral administration of crytaline glucosamine sulfate or glucosamine hydrochloride alone ir in combination with chondroitin sulfate. Osteoarthritis Cartilage 15(Suppl): C223-224.

Peterson L, Minas T, Brittberg M, Nilsson A, SjogrenJansson E, Lindahl A (2000) Two- to 9-year outcome after autologous chondrocyte transplantation of the knee. Clin Orthop Relat Res 374: 212-234.

Piasecki DP, Spindler KP, Warren T, Andrish JT, Parker RD (2003) Intraarticular injuries associated with anterior cruciate ligament tear: findings at ligament reconstruction in high school and recreational athletes. Am J Sports Med 31: 601-605.

Reginster JY, Deroisy R, Rovati LC, Lee RL, Lejeune E, Bruyere O (2001) Long term effects of glucosamine sulphate on osteoarthritis progression: a randomized, placebo-controlled clinical trial. Lancet 357: 251-256.

Richy F, Bruyne O, Ethgen O, Cucherat M, Henrotin Y, Reginster JY (2003) Structural and symptomatic efficacy of glucosamine and chondroitin in knee osteoarthritis: A comprehensive meta-analysis. Arch Intern Med 163(13):1514-1522.

Rumberger JM, Wu T, Hering MA, Marshall S (2003) Role of hexosamine biosynthesis in glucose mediated up regulation of lipogenic enzyme mRNA levels: effects of glucose,glutamine, and glucosamine on glycerophosphate dehydrogenase, fatty acid synthesis, and acetyl-CoA carboxlase mRNA levels. J Biol Chem 278: 28547-28552.

Sandy JD, Gamett D, Thompson V, Verschachen C (1998) Chondrocyte-mediated catabolism of aggrecan: aggrecanase-dependant cleavage induced by IL-1 or retinoic acid can be inhibited by glucosamine. Biochem J 335: 59-66.

Sawitzke AD, Shi H, Finco MF, Dunlop DD, Bingham CO 3rd, Harris CL (2009) The effect of Glucosamine and/ or Chondroitin Sulphate on progression of knee osteoarthritis: a report from the glucosamine/chondroitin arthritis intervention trial. Arthritis Rheum 58: 3183-3191.

Setnikar I, Rovati LC (2001) Absorption, distribution, metabolism and excretion of glucosamine sulfate: A review. Arzneimittelforschung 51: 699-725.

Setnikar I, Giachetti C, Zanolo G (1984) Absorption, distribution and excretion of radioactivity after a single IV or oral administration of $\left[{ }^{14} \mathrm{C}\right]$ to the rat. Pharmatherapeutica 3: 538-550.

Shelbourne KD, Sanjiv J, Gray T (2003) Outcome of untreated traumatic articular cartilage defects of the knee. J Bone Joint Surg Am 85: 8-16.

Steadman JR, Briggs KK, Rodrigo JJ, Kocher MS, Gill TJ, Rodkey WG (2003a) Outcomes of microfracture for traumatic chondral defects of the knee: average 11-year follow-up. Arthroscopy 19: 477-484.

Steadman JR, Miller BS, Karas SG, Schlegel TF, Briggs KK, Hawkins RJ (2003b) The microfracture technique in the treatment of full-thickness chondral lesions of the knee in National Football League players. J Knee Surg 16: 8386.

Tiraloche G, Girard C, Chouinard L, Sampalis J, Moquin L, Ionescu M, Reiner A, Poole AR, Laverty S 
(2005) Effect of oral glucosamine on cartilage degradation in a rabbit model of osteoarthritis. Arthritis Rheum 52: 1118-1128.

Wada Y, Watanabe A, Yamashita T, Isobe T, Moriya H (2003) Evaluation of articular cartilage with 3D-SPGR MRI after autologous chondrocyte implantation. J Orthop Sci 8: 514-517.

Wang, C.J (2002) Treatment of focal articular cartilage lesions of the knee with autologous osteochondral grafts: A 2 to 4 year follow up study. Arch Orthop Trauma Arthrosc 122: 169-172.

Yates JW Jr (2003) The effectiveness of autologous chondrocyte implantation for treatment of full-thickness articular cartilage lesions in workers' compensation patients. Orthopedics 26: 295-301.

\section{Discussion with Reviewers}

Reviewer I: Surely the glucosamine sulphate is affected by the hydrochloride in the stomach? Can it then reach the circulation? Was the hydrochloride salt used in the other studies quoted?

Authors: A pharmacokinetic study (Setnikar et al., 1986, text reference) has shown that after oral administration of glucosamine sulphate, it is rapidly broken down to glucosamine and sulphate. The sulphate will be ionised completely in the stomach's hydrochloric acid and released to the blood stream. This dissociation will make all the glucosamine available for absorption to the small intestine. Once absorbed into the blood stream, glucosamine, which is independent of the original salt, becomes available to the body (Web ref, 1).

Reviewer I: Should the hydrochloride be given?

Authors: Glucosamine is also available as glucosamine hydrochloride and has been used widely even though there are limited studies of glucosamine $\mathrm{HCl}$ in humans (Fox and Stephens, 2007). Both salts (hydrochloride and sulphate), in their pure form, deliver equally effective amounts of the desired glucosamine to joint cartilage. This is because they will be broken down in the stomach's hydrochloric acid. Whereas in terms of bioavailability of glucosamine, a previous study (Setnikar et al., 1986; Web Ref. 1) has shown that $54 \%$ of the glucosamine that moves into the small intestine $(\mathrm{pH}$ 6.8) exists in its un-ionised form while $46 \%$ is in ionised form (the amine group is protonated and positively charged). In the blood ( $\mathrm{pH} 7.4)$ $75 \%$ of the glucosamine is present as the neutral amine while only $25 \%$ is ionised. Since ionisation or high polarity is an obstacle in crossing cellular membranes, the ability of glucosamine to exist predominantly in its less polar (unionised) form in the small intestine and even more in the blood contributes directly to its bioavailability. Therefore, the specific salt form is relevant only as a convenient delivery vehicle for glucosamine provided that the salt must readily dissolve in stomach acid $(\mathrm{HCl})$ when ingested. Preference between these 2 forms is normally based on their relative purity and economics.
Reviewer I: Do you accept that the defect is not chronic? Authors: While we do agree that the defect is not chronic, we could not describe it as being acute either. A lapse of 3 weeks from the time of injury to the time of repair was observed. Even in humans, this will not be considered acute let alone in rabbits. We could classify it as being sub-acute. Even then this would not be easy to be categorized as such as this may not be applicable in rabbits. Other models describing similar techniques have been described (Mierisch et al., 2003, text reference), who have made similar assumptions of the suitability for the time of repair using comparable models.

Reviewer I: Do you accept that using an alginate bead is not standard ACI?

Authors: Yes, we accept that alginate bead is not standard practice but it was practical in this study. It is also an accepted technique published elsewhere (Mierisch et al., 2003, text reference).

Reviewer II: Is the absorption of GS and CS by rabbits similar to humans? Are there studies to show this?

Authors: As far as we are aware, no studies have been carried out that have compared the absorption rates of both these compounds or have made direct comparison of the absorption rate in humans and rabbits.

Reviewer II: Was there any attempt made to show that GS and CS levels were increased in the synovial fluid of the rabbit knees?

Authors: This experiment was not conducted as it was outside the scope of this study. Furthermore this idea was not formulated as part of the research hypothesis owing to the knowledge that previous studies have demonstrated that an increase in the glucosamine concentration after the ingestion of GS and CS is definite. However, it has been argued that the levels seen the knee synovial fluid are insufficient to be compared to the effects observed in in vitro models. Regardless of these findings, it was clear in this study that the use of GS and CS had a definite positive effect on the repair of damaged and repair cartilage.

Reviewer II: Studies on cartilage healing in a rabbit model generally gives good results. Can the good results be extrapolated to humans without validation with a similar study in a larger animal, e.g., sheep or pig?

Authors: The rabbit has been accepted as a standard animal model in articular cartilage studies. The authors do not see any problem in extrapolating good results to human as this has been practiced in previous studies (Brittberg et al., 1996; O'Driscoll et al., 1988, text reference). This is taking into consideration the translational model conducted by Brittberg and Petterson using the rabbit as their ACI model before use in humans.

Reviewer III: Regarding Fig. 2, the repair cartilage tissue is very thin and one may argue that it could also be residual tissue of the articular cartilage, left behind after the defect was created. It would therefore be appropriate to show the 
histology of a fresh defect as well as a defect three weeks later, just prior to chondrocyte transplantation.

Authors: We agree with the reviewer that histological studies of the fresh defect prior to chondrocyte transplantation would be appropriate. However, in practice, this is impossible to conduct as there will be a need to sacrifice the rabbit in order to do the histological study of the defective site prior to transplantation of the rabbit. In this study, we did compare the left knee (unrepaired) to the right knee (implanted) of the same rabbit, thereby demonstrating that the rate and quality of healing were dissimilar between the treated and untreated knees. To ensure that there was no residual tissue left within the defect site at the end of the first surgery, care was taken to remove all possible tissues while ensuring that the subchondral bone was not breeched.

Reviewer III:: From Fig. 2 it appears that in ACI-treated knee joints there is a very thin repair cartilage tissue with possible advancement of the bone front. The repair process may be endochondral ossification ultimately leading to loss of articular cartilage. Please comment!

Authors: While this may be the case when observed with the naked eye, our histological sections have proven otherwise. This finding was confirmed by our independent histologists who have also provided us with the grading to demonstrate the quality of the cartilage tissue.

Reviewer III: It may be that GS/CS treatment may affect durability of the repair cartilage tissue. Do the authors have data at longer time points to assess durability?

Authors: We agree that time points we have used (3 months and 6 months) are short as compared to other studies in which rabbits were sacrificed at 2 year post- transplantation. This is part of the limitation of this study. Therefore, we have used younger animals in this study, which we believe will provide a more rapid response and therefore demonstrate better the effect of the surgical intervention in the pharmacotherapy treatment. We foresaw that this may have inherent problems giving a false impression of the repair even in the untreated site. To circumvent this problem, we proceeded in creating defects in both knees, but only repaired one knee and leaving the other knee as control. The control site provided the comparative data that demonstrates the rate at which natural repair will take place if the knee is left untreated. This study shows that almost no spontaneous improvement of the defective sites occurred during the repair process so that spontaneous healing in defective sites of young(-ish) rabbits is not a problem in this study.

\section{Additional References}

Brittberg M, Nilsson A, Lindahl A, Ohlsson C, Peterson L (1996) Rabbit articular cartilage defects treated with autologous cultured chondrocytes. Clin Orthop Relat Res 326: $270-283$.

Fox BA, Stephens MM (2007) Glucosamine hydrochloride for the treatment of osteoarthritis symptoms. Clin Interv Aging 2: 599-604.

Setnikar I, Giacchetti C, Zanolo G (1986) Pharmacokinetics of glucosamine in dog and in human. Arzneimittelforschung 36: 729-735.

\section{Web Reference}

Web Ref. 1. Www.nutrasense.com/gluchclvssul.html (accessed 28-12-2010). 